\title{
Fontes on-line em arquivos brasileiros: Reflexões sobre a Internet no ofício do historiador
}

\author{
Celeste Baumann, Elson Granzoto Junior, \\ Patrícia Moreira Nogueira, Paula de Castro Broda, \\ Renata Soares de Souza e Vanessa Neri Rodrigues ${ }^{1}$
}

\section{RESUMO}

Esta pesquisa está inserida em um momento no qual as Tecnologias de Informação e Comunicação (TICs) potencializam diariamente a interface entre preservação, divulgação e produção de conhecimentos históricos. Neste artigo, procuramos apontar brevemente o caminho por nós percorrido, ancorados pela leitura dos principais debates a respeito do tema. Subsidiados pela experiência do contato direto com os sites dos arquivos, foi nos permitido refletir acerca da situação atual das fontes on-line, seus processos de digitalização, critérios de seleção e a organização das fontes, ampliando o escopo para se pensar os usos possíveis da Internet para o ofício do historiador e os desafios futuros impostos pelas novas tecnologias.

\footnotetext{
${ }^{1}$ Alunos da graduação do curso de História da Universidade Federal de São Paulo, bolsistas do Programa de Educação Tutorial (PET), tutorados pelas Profa. Dra. Edilene T. Toledo e Profa. Dra. Marcia Eckert Miranda. Aproveitamos para agradecer imensamente a colaboração das alunas Carolina Carvalho e Verônica Calsoni Lima ao longo da pesquisa e ao Prof. Dr. Luís Filipe Silvério Lima, tanto no período em que foi tutor do grupo PET História da Unifesp, quanto depois, na revisão deste artigo e sugestões de bibliografia.
} 
Palavras-chaves: TICs, fontes on-line, arquivos brasileiros, internet, digitalização de documentos, pesquisa histórica.

\section{Introdução}

Desde o ano de 2009, o grupo PET-História ${ }^{2}$ da Universidade Federal de São Paulo (UNIFESP) desenvolveu uma pesquisa que examina a relação entre as Tecnologias de Informação e Comunicação (TICs) e a pesquisa Histórica. O trabalho aqui apresentado, intitulado "Fontes on-line nos arquivos brasileiros: reflexões sobre a Internet no ofício do historiador" visa apresentar a trajetória deste processo.

Durante o período dedicado ao tema, buscou-se problematizar a relação entre as TICs e o ofício do historiador, a partir da análise de dados concernentes à documentação on-line retirados de arquivos digitalizados e disponibilizados na web. Nosso principal objetivo foi elaborar um banco de dados com informações

\footnotetext{
${ }^{2} \mathrm{O}$ Programa de Educação Tutorial (PET) é vinculado ao MEC e desenvolve atividades nas áreas de pesquisa, ensino e extensão.
} 
sobre os acervos e as fontes disponíveis na Internet vinculadas aos arquivos brasileiros. $^{3}$

Ao longo do trabalho nos deparamos com a complexa política de seleção das fontes digitalizadas e sua divulgação on-line. Assim, nos foi possível refletir como a escolha da documentação colocada na web relaciona-se à própria função dos arquivos e quais as implicações desta disposição das fontes no que diz respeito ao ofício do historiador.

O objetivo desse artigo é expor os dados coletados e materiais desenvolvidos ao longo do trabalho, bem como apresentar brevemente o percurso bibliográfico que ancorou nossas reflexões, descrever o desenvolvimento e os desafios encontrados ao longo da pesquisa. Além disso, expomos alguns dos resultados e conclusões possíveis de serem percebidas neste vasto e mutável universo que compreende a relação entre a pesquisa histórica e as Tecnologias de Informação e Comunicação.

\footnotetext{
${ }^{3}$ Concomitantemente à produção deste artigo foi desenvolvido um banco de dados, no qual reunimos as fontes localizadas ao longo da pesquisa. Este banco está disponível para consulta local do público na universidade e em breve estará on-line junto à página do grupo PET-História. A disponibilização das informações visa auxiliar pesquisadores interessados ou mesmo professores que poderão trabalhá-las em sala de aula.
} 


\section{As novas tecnologias e as políticas de guarda de documentos}

Ao considerarmos as relações estabelecidas em uma configuração social no qual as TICs ganham um espaço cada vez mais central nas atividades de pesquisa, buscou-se por autores que pudessem trazer tais questões para o debate humanístico.

$\mathrm{O}$ advento da Internet e das formas de interação com o universo on-line na década de $1990 \mathrm{fez}$ com que as instituições públicas e os já polêmicos debates envolvendo a autenticidade das informações se tornassem objeto de intensa reflexão por parte do meio intelectual.

Ainda nos primórdios de ampliação da rede, uma tendência de reflexão sobre o ciberespaço preocupava-se com a autenticidade dos conteúdos e dos documentos disponibilizados na Web. A partir desta perspectiva alertava-se, então, para o cuidado que o pesquisador deveria ter ao lidar com esse tipo de informação, uma vez que não haveria como controlar o fluxo de dados inseridos e disponibilizados on-line.

O historiador Charles Dollar defende que é preciso questionar tais dados on-line, observando, principalmente, a sua "procedência, criação e preservação" que, segundo ele, são essenciais para a avaliação das informações (Dollar, 1994: 75). Suas constatações fazem bastante sentido, principalmente se 
considerarmos o contexto de sua produção, no qual a inserção de informações na rede mundial de computadores estava no começo de uma imensa intensificação e disseminação, levando os profissionais, como os da História, a refletirem sobre o futuro dos arquivos e da autenticidade dos documentos.

Pierre Lévy discordou dessa opinião, percebendo este processo de disseminação cibernética sob um diferente viés. Ainda que parta da mesma discussão, ele defende a "virtualização" como uma resposta a uma demanda da sociedade que somente teria modificado as suas formas de comunicação. Assim, essa virtualização corresponderia às transformações sociais de cunho mais democrático, algo que já vinha sendo feito por outras mídias, como a televisão. Desta forma, seria possível afirmar que tais tecnologias estariam, portanto, "disponíveis para todos". Utilizá-las ou não seria, assim, uma questão de escolha (Lévy, 1999).

Em linhas gerais, as posições dessas duas tendências marcam o debate sobre o papel dos arquivos e das novas tecnologias empreendido nos anos 1990. Enquanto a primeira demonstra cautela e preocupação com a intensificação da disponibilização de informações na web, a segunda observa o fenômeno com entusiasmo, inserindo-o num processo maior, iniciado por outras mídias. 


\section{Cadernos de Clio, Curitiba, n. ${ }^{\circ}$ 3, 2012}

Distanciando-se das perspectivas anteriores, Manuel Castells coloca outra tendência e argumenta que é impossível desassociar a sociedade das tecnologias existentes (Castells, 2000). Assim sendo, não compactua nem com a preocupação da primeira no que se refere à questão da autenticidade dos documentos, nem com a percepção otimista da segunda ao enxergar a virtualização como uma demanda social que promoveria a democratização das informações. Nesse sentido, pensando na relação entre a tecnologia e a sociedade, Castells refere-se a uma "sociedade interativa", isto é, pautada na linguagem como forma de mediação e de determinante cultural. Tal linguagem aplicada à Internet potencializaria a capacidade de comunicação na medida em que é, em geral, "espontânea, não-organizada e diversificada" em suas finalidades e forma de adesão.

No final dos anos 2000, o historiador Robert Darnton refletiu sobre a relação entre disseminação do conhecimento e direitos de propriedade (Darnton, 2010). A ideia sustentada pelo autor associa a democratização de informações à questão do copyright. ${ }^{4} \mathrm{O}$ autor analisa os impasses inerentes à digitalização e as ações que repercutiram deste processo. Para tanto, Darnton se

\footnotetext{
${ }^{4}$ Cabe ressaltar que o Copyright diz respeito ao direito de reprodução sobre determinada obra, diferentemente do Direito Autoral, que se refere à produção intelectual do autor.
} 
vale como exemplo da empresa Google, que possibilita a preservação e recuperação de artigos ou livros de difícil acesso, fora de circulação e/ou danificados, ampliando, em teoria, o acesso dessas obras à população geral. É vetado aos leitores, entretanto, a possibilidade de imprimir livros, cujo copyright ainda esteja sob domínio de um autor ou editora e, neste caso, a visualização das obras também é apenas parcial. Além disso, o acesso a todos os livros disponibilizados pelo Google só se dá mediante uma assinatura para "licença de consumo", assinatura esta que, segundo Darnton, estaria disponível para universidades e instituições públicas.

Darnton atenta, portanto, para o perigo da comercialização, pois os livros deixariam de ser percebidos como "fontes do saber" para serem vistos como "investimentos". É neste sentido que, segundo o historiador, o Google olha para as obras - um espaço cheio de "conteúdos" prontos para serem garimpados, uma vez que a digitalização dos acervos poderia ser feita a um baixo custo, se comparado ao investimento que receberiam, em especial graças a assinaturas e à publicidade. Para Darnton, ainda que a intenção seja uma distribuição "democrática" das obras, está se formando um "monopólio do saber", pautado na falta de interesse das autoridades públicas para digitalização de livros.

E foi tomando ciência de tais leituras e debates apontados 
por esses autores que, de certa forma estão em consonância com nossa pesquisa, que tiramos algumas conclusões a respeito de questões em torno do debate da arquivística e sua relação com o ofício do historiador e suas pesquisas.

\section{Procedimentos da pesquisa: listagem, tabulação e análise dos dados}

O projeto teve como mote principal pensar as tecnologias digitais e seu uso por arquivos e bibliotecas. Esperávamos compreender, naquele primeiro momento, como as instituições se apresentavam em uma plataforma virtual e disponibilizavam o conhecimento a elas destinado; qual era a relação entre o conteúdo disposto em suas páginas da web e o acervo que abrigam e, em última análise, como se dava a democratização: o acesso dessas fontes on-line em paralelo às reflexões trazidas por Perry Lévy.

O contato inicial com nossas fontes se deu por meio da elaboração de uma listagem dos arquivos e bibliotecas on-line ao redor do mundo, a fim de observarmos quais itens seriam encontrados e se haveria algum padrão na disponibilização de documentos na rede. Deste modo, procurávamos observar as informações das instituições, as ferramentas referentes à pesquisa virtual e seu acervo on-line, caso existisse. 
A partir da primeira sondagem, elaborou-se uma ficha experimental com a qual se pretendia identificar um conjunto de dados, tais como: proveniência do acervo, o(s) responsável(eis) por sua digitalização, fatores que teriam ocasionado o processo em questão. A pluralidade e incompatibilidade de elementos, a dispersão de informações e sua desorganização nos sites levaram, além de uma atualização da ficha, ao recorte da busca, restringindo a investigação aos arquivos públicos e privados brasileiros, que foram levantados por meio de pesquisa realizada em Dezembro de 2010.

O levantamento revelou um total de 413 arquivos, reunidos a partir de uma relação disponível no site do Conselho Nacional de Arquivos (CONARQ), ${ }^{5}$ somada à procura sistemática em sites de busca e homepages oficiais de estados e municípios, para completar eventuais lacunas à relação on-line. Nesta listagem, cada arquivo pesquisado foi classificado por região e estado, discriminando se possuía ou não site e, por fim, se suas páginas na web disponibilizavam algum tipo de conteúdo on-line, como demonstram os gráficos a seguir:

\footnotetext{
${ }^{5}$ Disponível em

<www.conarq.arquivonacional.gov.br/cgi/cgilua.exe/sys/start.htm>. Último acesso em 07 de junho de 2011.
} 


\section{Arquivos levantados}

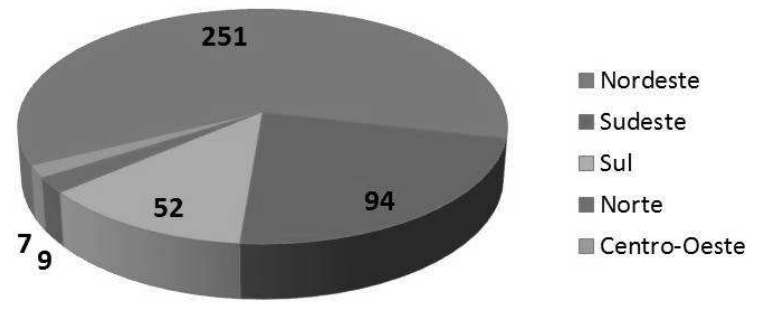

\section{Arquivos que possuem domínios na Web}

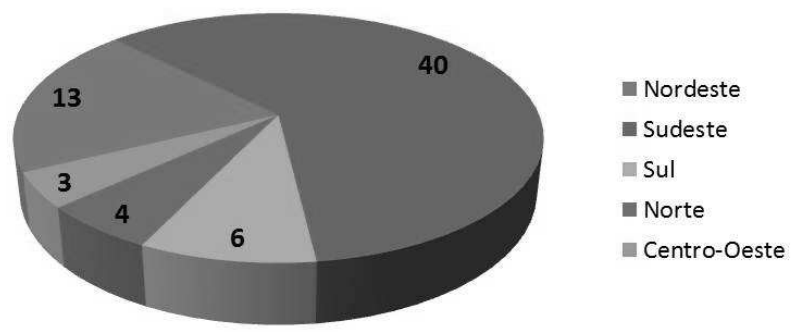


A última etapa da tabulação ainda indicou que, dos 413 arquivos localizados, apenas doze disponibilizam algum tipo de conteúdo digitalizado ao seu público. Tais arquivos estão divididos em cinco estados, sendo eles: São Paulo, Rio de Janeiro, Minas Gerais, Santa Catarina e Paraná, sendo possível notar preponderância da região Sudeste sobre as demais, ao comportar dez das doze instituições que disponibilizam fontes digitalizadas. Outro dado importante é o total de homepages: doze ao todo, sendo cinco domínios municipais, quatro estaduais, dois particulares, mas que apresentam conteúdos referentes à memória da esfera pública e um site de domínio federal, ligado ao Ministério da Cultura. Também é notável a especificidade apresentada pela região Nordeste que, embora comporte mais da metade dos arquivos relacionados, possui somente treze deles com páginas na web e nenhum com qualquer tipo de fonte digitalizada. 


\section{Arquivos que disponibilizam fontes on-line}

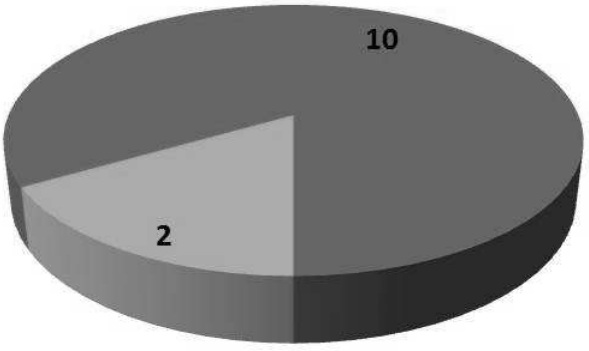

nordeste

- Sudeste

- Sul

norte

Centro-Oeste

Tais dados sugerem um predomínio de arquivos nas esferas municipal e estadual, sendo menos expressivo no que diz respeito ao Governo Federal. É possível pensar, por exemplo, a concentração de fontes on-line justamente em arquivos de regiões que apresentam economia mais dinâmica. Isso nos leva a refletir acerca da disponibilização de informações, bem como sua vinculação a questões políticas e econômicas que ultrapassam os interesses de determinados arquivos e que nos levam a pensar sobre como algumas instituições são percebidas e se fazem presentes no cotidiano nestas três esferas. 
Após essa reunião de dados, o passo seguinte consistiu na aplicação da ficha aos doze sites dotados de fontes on-line. No período entre Janeiro e Março de 2011 foram fichados os sites das seguintes instituições:

- Acervo Histórico da Assembléia Legislativa do Estado de São Paulo,

- Arquivo Geral da cidade do Rio de Janeiro

- Arquivo Histórico da Câmara Municipal de Itapetininga

- Arquivo Municipal de Criciúma

- Arquivo Público do Estado de São Paulo

- Arquivo Público do Município de São José dos Campos

- Arquivo Público do Paraná

- Arquivo Público Mineiro

- Centro de Documentação e Pesquisa da História Contemporânea do Brasil - CPDOC/FGV

- Fundação Arquivo e Memória de Santos

- Fundação Nacional das Artes - Funarte

- Intercâmbio, Informações, Estudos e Pesquisas - IIEP 
O procedimento, porém, não tardou a revelar que diversas das informações procuradas não se adequavam ao nosso último modelo de ficha. Por este motivo, nosso material foi mais uma vez reformulado, tendo como base as informações encontradas nos arquivos e na bibliografia utilizada neste processo, que além de auxiliar nossas ponderações acerca do universo digital, também apoiaram nossas análises sobre o tratamento de acervos e a transposição em relação ao suporte digital.

Nesta etapa, utilizamos a ficha para levantar os seguintes dados: apresentação do site (a qual instituição pertence, quem o desenvolveu, quais seus objetivos/metas); como se deu o projeto de digitalização (quem foi o responsável, quais as instituições envolvidas, se houve alguma forma de patrocínio e quais os critérios para a seleção das fontes digitalizadas); como é sua coleção digitalizada (proveniente de qual acervo, qual seu modo de acesso e a disponibilização, qual formato de visualização dos documentos JPG, PDF, TIF etc. - e como funciona seu sistema de busca); quais e como estão divididas as fontes encontradas ali (tipologia, categoria, período, a qual fundo e coleção pertencem).

Ao final de cada levantamento ainda foram elaboradas palavras-chave para identificação do arquivo analisado, além de 
uma pequena descrição da página, relatando problemas encontrados ao longo do processo, críticas e pontos positivos do site pesquisado.

\section{"Vitrine" virtual: o que é digitalizado e publicado}

Finalizados os levantamentos, foi possível refletir com mais propriedade a respeito dos resultados obtidos ao longo do processo de pesquisa. A tabulação dos dados e sua consequente sistematização trouxeram à tona certas questões que nos levaram a pensar sobre os problemas da digitalização, considerando ainda 0 método de divulgação, circulação e disponibilização das informações digitalizadas, bem como os critérios e procedimentos referentes à escolha dos materiais dispostos na rede.

A análise destes pontos serviu como fio condutor da pesquisa e possibilitou uma reflexão a respeito da conjuntura atual dos acervos em arquivos públicos no Brasil e como estes têm lidado com a informatização de seus sistemas, além de discorrer sobre os recursos utilizados por cada local ou região. Deste modo, nosso exame inicial revelou outro importante aspecto ligado à Arquivística que, aparentemente, tem sido desconsiderada por essas instituições. Cada arquivo lida de forma diferenciada com seu acervo e sua reprodução digital, podendo digitalizá-lo por completo e contemplá-lo com um sistema de busca informatizado ou apenas 
dar publicidade a uma pequena parte do conjunto documental, sem que esses critérios sejam explicitados ao consulente. Assim, observamos a ausência de padronização e de organização, mesmo particular e interna de cada acervo com relação ao material selecionado para ser disposto na web.

Além disso, foram raras as vezes que encontramos informações técnicas sobre as instituições, tais como as dimensões do acervo disponível para consulta, ou o responsável pela definição dos critérios de disponibilização on-line da documentação. Poucos arquivos, por exemplo, apresentam em seus sites informações sobre os critérios de seleção dos documentos ali dispostos. Outro dado desconsiderado pelas instituições é a proporção das fontes on-line em relação à totalidade do acervo.

De todos os arquivos com site pesquisados, percebemos que o Arquivo Público do Estado de São Paulo é o que possui as descrições mais completas, bem como o Centro de Pesquisa e Documentação de História Contemporânea do Brasil (CPDOC).

Quanto ao critério de seleção, identificamos que o Arquivo do Estado de São Paulo tem sua documentação disponibilizada com objetivo principal de divulgar fontes de variadas tipologias, ligadas aos principais fatos da História do Estado de São Paulo, e relata, em sua página na web, que estão disponíveis on-line 48,16 metros lineares de documentos digitalizados, relacionados aos temas de 
administração pública, urbanização, industrialização, movimentos sociais, educação estadual, grupos escolares, imigração e modos de vida em São Paulo ${ }^{6}$. Todos dispostos em documentos iconográficos, impressos, fílmicos, cartográficos e manuscritos, que podem ser visualizados em PDF ou JPEG. Seu acesso pode ser feito na área principal do site, na seção "Acervo Digitalizado". O AESP possui, também, um sistema de busca simples e organizado, mas em geral é preciso verificar todo e qualquer link em busca de mais informações.

Percebemos, ainda, dificuldades ao diferenciar fundos de coleções, para além de problemas pontuais com os sistemas de busca disponíveis e ainda uma falta, ou mesmo insuficiência, no uso de palavras-chaves. Muitas instituições não apresentavam nenhuma divisão entre fundos e coleções, porém, em outras, conseguimos deduzir algumas destas categorias a partir das nossas diversas leituras e releituras ${ }^{7}$ e das relações de documentos com que tivemos contato. Toma-se como exemplo de organização de fundos e de critério de disponibilização, o site do CPDOC que, como agregador

\footnotetext{
${ }^{6}$ Observa-se que as informações aqui dispostas são referentes a dados coletados em meados de 2010 e início de 2011.

${ }^{7}$ Entre as leituras realizadas a esse respeito destacamos: BELLOTTO, Heloísa Liberalli. Arquivos permanentes: tratamento documental. $4^{\mathrm{a}}$ ed. Rio de Janeiro: FGV, 2006; GONÇALVES, Janice. Como classificar e ordenar documentos de arquivo. São Paulo: Arquivo do Estado, 1998. Disponível em: <http://www.arqsp.org.br/CF02.pdf>. Acesso em ago. de 2011.
} 


\section{Cadernos de Clio, Curitiba, n. ${ }^{\circ}$ 3, 2012}

de acervos particulares de várias personalidades brasileiras, dispõe de uma imensa variedade de assuntos e experiências pessoais do cotidiano, que é uma organização preocupada em disponibilizar somente fundos completos.

Para além dessas questões, também nos chamou a atenção o predomínio na escolha de fontes imagéticas para divulgação na web, sobretudo a de fotografias com relação às demais. Um exemplo disso é o caso da Fundação Arquivo e Memória de Santos, instituição municipal, localizada no Estado de São Paulo, que só disponibiliza documentos imagéticos que representam os marcos considerados mais significativos para cidade e eventos promovidos pela própria Fundação. Para tais fontes não há informações a que fundo pertencem, sendo separadas pelas categorias: Bombeiros, Bondes, Gonzaga, Hotéis, Igrejas, Monumentos, Panorâmicas, Ponta da Praia, Porto, Praças, Praias, Rua do Comércio, Serviço Público e Exposições.

A recorrência deste tipo de fonte pode revelar, por exemplo, uma tendência dos arquivos, que buscariam disponibilizar em suas homepages documentos que "chamassem a atenção" do público de forma mais direta, servindo assim, em certa medida, como uma espécie de "vitrine" do que se pode encontrar no acervo. Tal estratégia, entretanto, corre o risco de subutilizar as potencialidades da digitalização, que poderia ser vista apenas como 
atrativa ou mera ilustração de seu conteúdo e não como uma possível fonte que pode ser problematizada. É possível também que tal escolha limite a função pedagógica e cultural das instituições, sugerindo que a finalidade destes documentos seja uma forma de "despertar a curiosidade" do público-alvo, e não fonte para a produção de conhecimento histórico ${ }^{8}$.

Para além dos problemas encontrados com a ausência de clareza de critérios de seleção e disponibilização das fontes, identificamos também, no que diz respeito à organização dos acervos, um problema ligado à Arquivística. Nesse sentido, buscamos na obra de Heloísa Bellotto a metodologia de tratamento documental, a fim de pensarmos sobre a relação da Arquivística com os documentos dispostos na Internet:

\footnotetext{
${ }^{8}$ Cabe aqui, ressaltar que a cultura visual contemporânea é assunto que permeia a questão do uso imagético como fonte para a pesquisa histórica, em muitos casos tratada apenas como ilustração (como o observado no exemplo citado). É importante que se tome consciência deste tipo de documento para a produção do conhecimento histórico. Entretanto, por uma questão de delimitação do tema, não entramos nesta área, mas sugerimos alguns artigos do Prof. Dr. Ulpiano Bezerra de Menezes que tratem dessa temática: MENESES, Ulpiano T. Bezerra de . "Fontes visuais, cultura visual, História visual. Balanço provisório, propostas cautelares". Revista Brasileira de História, São Paulo, v. 23, n. 45, p. 11-36, 2003; MENESES, Ulpiano T. Bezerra de . "A fotografia como documento. Robert Capa e o miliciano abatido na Espanha: sugestões para um estudo histórico". Tempo - Revista do Departamento de História da UFF, Niterói, v. 7, n. 14, p. 131-142, 2003.
} 
Cadernos de Clio, Curitiba, n. ${ }^{\circ}$ 3, 2012

Um arquivo permanente não se constrói por acaso. Não cabe apenas esperar que the sejam enviadas amostragem aleatórias. A história não se faz com documentos que nasceram para serem históricos, com documentos que só informem sobre o ponto inicial ou o ponto final de algum ato administrativo decisivo (Bellotto, 2006: 27).

Desta forma, entendemos que se faz necessário refletir sobre como tais documentos são recolhidos e arranjados nos arquivos permanentes e sobre as implicações da avaliação documental em relação às possibilidades de pesquisa histórica. É preciso, deste modo, que os princípios da Arquivística sejam observados também em seus territórios virtuais, para que haja uma consonância do que está presente nos acervos físicos e em suas contrapartes digitais, não só prezando por uma organização, mas também garantindo um acesso pleno a tais documentos. A ampliação do acesso à informação pelo meio virtual deve, especialmente, garantir o conhecimento e, para tanto, é preciso mostrar de forma clara quais os processos e objetivos envolvidos na divulgação de tal conteúdo, a fim de cumprir a função arquivística no que concerne a sua dimensão social e cultural.

É possível pensar a própria digitalização dentro dessa dimensão social, uma vez que possibilita maior visibilidade à memória pública por meio das fontes on-line e ainda a 
"democratização" dessas informações a um maior número de usuários na Web, mesmo que, como apontamos, essa divulgação da documentação seja problemática. Outro fator interessante é a questão do "monopólio do saber" levantado por Darnton que, até onde pudemos constatar, não se aplica ao caso dos arquivos brasileiros, pois estes não capitalizam recursos por meio da disponibilização as informações. Porém, o próprio fato de apenas 12 dentre os 413 arquivos levantados possuírem fontes on-line pode apontar uma possível falta de interesse das autoridades públicas nesta divulgação de conhecimento na Internet.

\section{Apontamentos para os usos possíveis da Internet para o ofício do historiador}

Ao longo desta pesquisa, procuramos nos familiarizar com as discussões a respeito do universo digital, percebendo sua relevância para questões concernentes ao espaço ocupado pelos pesquisadores em História. Acreditamos que a reflexão sobre o futuro dos arquivos e as TICs é de extrema importância, sendo preciso que haja um maior intercâmbio de ideias entre historiadores e arquivistas neste campo.

Sem dúvida o trabalho de digitalização e disponibilização de fontes na Internet é um processo contínuo, que precisa e deve ser expandido, pois possibilita a ampliação do compartilhamento de 
material entre historiadores e também ao público em geral interessado, como comumente ocorre no Brasil, por exemplo, com relação aos arquivos ligados à imigração (Paiva, 2009: 1-17). A necessidade dessas medidas, contudo, não pode anuviar a importância dos métodos organizacionais para esta crescente documentação que vem sendo disponibilizada virtualmente.

É perceptível o crescente destaque dado pelo historiador no que se refere ao mundo virtual, e a aproximação com os arquivos on-line é um possível meio para o aprofundamento de diversas ideias. A forma como os arquivos disponibilizam os documentos interfere na sua utilização pelos pesquisadores. Pode-se refletir, então, em que medida a disposição das fontes condiciona até mesmo as temáticas de pesquisa. A (in)disponibilidade de acesso virtual aos documentos pode determinar a viabilidade da execução da pesquisa, na impossibilidade do contato com o acervo.

Nesse sentido, as instituições exercem um papel fundamental, visto que, selecionam os documentos a serem digitalizados. Conforme os arquivos disponibilizam conjuntos documentais, suscitam e até mesmo direcionam o interesse para novas temáticas de pesquisa. Entretanto, como notamos ao longo do levantamento dos dados dos sites, os critérios de escolha e os interesses possíveis que a fonte representa para a pesquisa histórica não são definidos e expostos aos pesquisadores. De fato, a ausência 
de uma política de seleção mais rigorosa pode acarretar um distanciamento entre arquivo e pesquisador.

Uma disponibilização sistemática e intensa das fontes no meio on-line (e não uma amostragem de documentos) pode não apenas preservar a documentação em seu suporte original, como igualmente contribuir para maior produção de conhecimento.

Faz-se necessário apontar que a adoção de medidas de salvaguarda digital ${ }^{9}$ tem sido discutida em todo o mundo. Dentre estas iniciativas podemos destacar no Brasil as "Recomendações para Digitalização de Documentos Arquivísticos Permanentes" do CONARQ ${ }^{10}$ e a "Carta do Recife" vinculada a Rede Memorial. ${ }^{11}$ Ações estas que partem do princípio de que

(...) a digitalização dos acervos culturais do Brasil tem se tornado uma tarefa de grande urgência, solicitando uma reflexão sobre os limites impostos pela atual legislação do direito autoral, as novas tecnologias, os padrões e normas, assim como os caminhos para a formação de uma rede efetiva entre as instituições e os projetos já existentes (Carta do Recife, 2011: 02).

\footnotetext{
${ }^{9}$ A digitalização não implica na exclusão da documentação original.

${ }^{10}$ CONARQ. 'Recomendações para Digitalização de Documentos Arquivísticos Permanentes, 2010. Disponível em:

<www.conarq.arquivonacional.gov.br/media/publicacoes/recomenda/recomendae s_para_digitalizao.pdf>. Último acesso em 27 de janeiro de 2012.

${ }^{11}$ REDE MEMORIAL. Carta do Recife, 2011. Disponível em: $<$ http://redememorial.org.br/Pagina_inicial_files/REDE_MEMORIAL_Carta_do _Recife_br.pdf>. Último acesso em 27 de janeiro de 2012.
} 
Tal processo, todavia, precisa ser efetivado "não apenas a partir de uma profunda reflexão e planejamento, mas também da experiência acumulada pelos atores efetivamente envolvidos com a digitalização dos seus acervos" (Carta do Recife, 2011: 02). Se este trabalho for realizado junto às diversas instituições envolvidas com a salvaguarda da documentação, as dificuldades com relação à seleção e publicização das fontes on-line por nós identificadas têm grandes chances de ter os seus efeitos suavizados.

Uma questão relevante, neste ponto, é a forma de disposição da documentação proposta por tais cartas que, de modo geral, visam à organização dos suportes digitais, mas não mencionam os princípios de organização arquivística utilizados nos acervos originais. Esta discussão nos interessa, pois, para além da variedade de linguagens (.PDF, .JPG etc.), a maior dificuldade encontrada ao longo da pesquisa foi justamente com relação à metodologia arquivística, que apresenta disparidades relevantes no tratamento dos acervos e das fontes digitalizadas. ${ }^{12}$

Muitas das questões discutidas ao longo deste artigo se encontram em aberto, sendo necessária a maior participação dos agentes interessados na promoção das mudanças almejadas.

${ }^{12}$ Em relação aos princípios arquivísticos de organização, ver: BELLOTTO, Heloísa Liberalli. Arquivos Permanentes. Tratamento documental. Rio de Janeiro: FGV, 2006. 
Procuramos, aqui, apenas apontar brevemente o caminho por nós percorrido ao longo da pesquisa e as questões norteadoras que surgiram a partir do contato direto com os sites dos arquivos, bem como a leitura dos principais debates a respeito do tema. Este é, antes, um esforço de ampliação do escopo para se pensar os usos e limites da Internet para o ofício do historiador e os desafios futuros impostos pelas novas tecnologias.

\section{Bibliografia}

BACELLAR, Carlos. "Fontes Documentais: uso e mau uso dos arquivos". In: PINSKY, Carla B. (org.). Fontes históricas. São Paulo: Contexto, 2006.

BELLOTO, Heloisa Liberalli. Arquivos permanentes. Tratamento documental. Rio de Janeiro: FGV, 2004.

CASTELLS, Manuel. A sociedade em rede. São Paulo: Paz e Terra, 2000.

DARNTON, Robert. "O Google e o futuro dos livros". In: A questão dos livros: passado, presente e futuro. São Paulo: Cia. das Letras, 2010. Disponível em:

$<$ http://baixacultura.org/2010/07/06/robert-darnton-e-o-googlebooks/>. 
DOLLAR, Charles. Tecnologias da informação digitalizada $e$ pesquisa acadêmica nas ciências sociais e humanas: o papel crucial da arquivologia. Estudos históricos, n.13, 1994.

FERRARI, Terezinha. A esfinge do ciberespaço. Projeto História. São Paulo, n.34, jan. 2007, pp. 271-87. Disponível em: $<$ http://revistas.pucsp.br/index.php/revph/ article/viewFile/ 2476/1571>.

FIGUEIREDO, Luciano. "Historia e Informática: o uso do computador". In: Cardoso, Ciro Flamarion (org.); Vainfas, Ronaldo (org.). Domínios da história: ensaios de teoria e metodologia. Rio de Janeiro: Elsevier, 1997.

LÉVY, Pierre. "O Digital ou a virtualização da Informação". In:

Cibercultura. São Paulo: Editora 34, 1999.

PAIVA, Odair da Cruz. Arquivos da Imigração no contexto da Hospedaria de Imigrantes de São Paulo. UNESP - FCLAs CEDAP, v. 5, n.2, pp. 1-17, Dez. 2009.

\section{Documentos consultados}

CONARQ. 'Recomendações para Digitalização de Documentos Arquivísticos Permanentes, 2010. Disponível em:

<www.conarq.arquivonacional.gov.br/media/publicacoes/recomend a/recomendaes_para_digitalizao.pdf $>$.

. Relação de arquivos públicos brasileiros. Disponível em:

<www.conarq.arquivonacional.gov.br/cgi/cgilua.exe/sys/start.htm 
REDE MEMORIAL. Carta do Recife, 2011. Disponível em:

$<$ http://redememorial.org.br/Pagina_inicial

_files/REDE_MEMORIAL_Carta_do_Recife_br.pdf>.

\section{Sites analisados}

Acervo Histórico da Assembléia Legislativa do Estado de São Paulo. Disponível em:

<http://www.al.sp.gov.br/web/acervo2/index_acervo.htm>. Acesso em 2010.

Arquivo Geral da cidade do Rio de Janeiro. Disponível em: <www0.rio.rj.gov.br/arquivo>. Acesso em 2010.

Arquivo Histórico da Câmara Municipal de Itapetininga. Disponível em:<www.camaraitapetininga.sp.gov.br/camara/index/conteudo.ph p?filtro=item\&item_id=1537> Acesso em janeiro de 2011.

Arquivo Municipal de Criciúma. Disponível em:

<www.criciuma.sc.gov.br/arqhistorico.php>. Acesso em 2010.

Arquivo Público do Estado de São Paulo. Disponível em:

<www.arquivoestado.sp.gov.br/index.php>. Acesso em 2010.

Arquivo Público do Município de São José dos Campos. Disponível

em: <www.camarasjc.sp.gov.br/promemoria〉. Acesso em 2010.

Arquivo Público do Paraná. Disponível em:

<www.arquivopublico.pr.gov.br>. Acesso em janeiro de 2011.

Arquivo Público Mineiro. Disponível em:

<www.siaapm.cultura.mg.gov.br/>. Acesso em 2010.

Centro de Documentação e Pesquisa da História Contemporânea do Brasil - CPDOC/FGV. Disponível em:

<http://cpdoc.fgv.br/acervo/arquivospessoais>. Acesso em janeiro de 2011.

Fundação Arquivo e Memória de Santos. Disponível em: 
Cadernos de Clio, Curitiba, n. ${ }^{\circ}$ 3, 2012

<www.fundasantos.org.br/galeria/main.php>. Acesso em 2010.

Fundação Nacional das Artes - Funarte. Disponível em:

<www.funarte.gov.br>. Acesso em janeiro de 2011.

Intercâmbio, Informações, Estudos e Pesquisas - IIEP. Disponível em: <www.iiep.org.br>. Acesso em 2010. 